\title{
Transforming Urban Public Transportation: A Lean Enterprise Approach
}

Dennis F.X. Mathaisel, Babson College

Scott A. Hirsch, Accenture

Clare L. Comm, University of Massachusetts Lowell

\begin{abstract}
Much urban mass transportation is perceived as providing second-rate service, existing for the disenfranchised, and possibly not being safe. Once, mass transit recognized and filled a need in major urban areas for efficient intra-city transportation, but people's needs have changed. The goal of this paper is to characterize the current state of urban mass transportation and develop a practical multi-disciplinary business-oriented approach to reenergize transit and to form the type of mass appeal that cars and passenger airlines have. Based on a Lean Enterprise Architecture for transforming the public sector, and using global examples, the authors propose a plan of action to improve and change the image of urban mass transportation.
\end{abstract}

Keywords: Public Sector Transformation, Lean Enterprise Architecture

\section{INTRODUCTION}

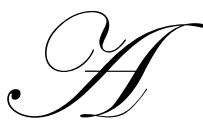

lthough mass transit is one of the most efficient modes of transportation in major urbanized areas, some public transportation has earned itself a long-standing reputation as being dirty and slow and as existing to serve the poor and disenfranchised. In many parts of the world, transit has been neglected and under-funded for so long that some public officials have given up on fixing it. In addition, recent security concerns have arisen for passengers as a result of the Madrid, London, and India terrorist attacks.

Many urban mass transit agencies (UMTs) are outmoded because their customers' needs have changed while mass transit has continued to operate in the same manner. Since demand for urban public transit services dropped after World War II, UMTs have ignored the problem of attracting customers back to public transit by passively blaming the problem on external factors, such as the perceptions of urban mass transit, the economy, politicians and budgets, and the public's love of cars. These attitudes have negatively impacted the mass transportation world. Agencies may only be able to compete today by transforming the entire enterprise and not just one aspect of it.

Many transit executives have little incentive to be innovative or improve upon their agencies' operations. Their current models are focused almost entirely on expansion, not on providing first class customer service. As a result, UMTs' core customers, except for those in very densely populated areas, have almost abandoned the mode. Many argue that transit is so under-funded in some countries that options do not exist for agencies to make improvements. Nevertheless, before agencies propose building expensive new lines or purchasing new equipment, they must deal with issues that will be present whether they operate new or old buses or rail cars.

Urban mass transportation marketers would probably have a difficult time convincing the general public that improvements in a few aspects of their operations could make a lot of difference. But, as Malcolm Gladwell (2000) points out in his book, The Tipping Point: How Little Things Can Make a Big Difference, change at the margin can have dramatic effects. Gladwell argues in his book "ideas and products and messages and behaviors spread just like viruses do," causing a situation to "tip." Applying Gladwell's thinking to urban mass transit, one can see that increasing the use of public transportation will require a significant "tip." As he indicates, the way tips 
do happen, especially in the case of public transit and in light of people's negative attitudes toward it, are through incremental changes. Thus, transit agencies might be able to realize more success in serving the public if they maximize existing resources. This is especially true for cities like London, New York, and Boston, which have had operational systems for a long time and already have extensive infrastructures.

UMT executives maintain that the car is to blame for the decline of transit. Thus, UMTs should focus on defining their competitive business advantage over other modes of transportation in urban areas. To serve the public in the best way possible, transit must transform itself as an enterprise that is more acceptable to the public. This is not easy since the general public has strong preconceived negative ideas about mass transit. Therefore, riding public transit must become part of people's lifestyles in order for the general public to adopt it.

An example of a strategy that could be used to get new riders is by attracting customers one at a time. The campaign that might attract people to transit would convince potential customers to give transit a chance and to see how their lives could be improved by using transit. They, in turn, would convince other people to give transit a chance. This is referred to as the Diffusion Process of Innovation (Robertson, 1967).

Of course, improving the transit experience for customers will be critical to attracting and, most importantly, keeping new customers. An example of an effective tool that has been developed and operated by SocialData is Individualized Marketing (IM) or Travel Smart. The program relies on getting the word out about transit and providing alternatives for people to consider when they decide how to get around (Jowit, 2003). This method employs direct marketing techniques to inform potential customers about public transit and alternatives to the automobile. Compared to building new transit lines or purchasing more buses, this method is very inexpensive. For example, customers may request more information on the value that transit provides. Agencies can then send them information tailored to their needs. In some cases, agencies will even send a consultant to explain different routes of the system and how the system works. SocialData originated in Munich and is mainly used in Western Europe, Australia, and more recently in Portland, Oregon.

However, UMTs are slow to innovate with techniques such as Travel Smart because they do not operate in a directly competitive environment with each other. They do compete with other modes of transportation, including the automobile, taxis, walking, and bicycling. Many political stakeholders and watchdogs keep tabs on UMTs, and they compete with other agencies for public funding. The problem is that many UMT executives lack the correct tools and methodology to support effective strategic decision-making. The models which UMTs use in project appraisal "rarely forecast accurately for schemes with long planning periods and long project lives" and provide an incomplete suboptimal picture (Mackie and Preston, 1998). As a result, urban mass transportation agencies do not have a truly integrated enterprise-wide outlook on their problems. In order to get potential customers to use public transportation, UMTs must look past the assumptions which economic models make and take a more enterprisewide strategic approach.

An example of how limiting some economic models can be is illustrated in a recent study of fare-free transit conducted at the University of California, Los Angeles (UCLA). A few experiments have attempted to offer solutions for the public transit ridership problem by demonstrating that fare-free transit has the potential to significantly increase usage of public transportation. Various experiments have been conducted all over the United States. One of the most recent occurred at UCLA. In each of the experiments that have taken place, the studies have shown that fare-free transit does have a significant effect on ridership of public transit (Shoup et al, 2003). However, the net effect of reduced fares is marginal because the new ridership is not coming from people who were driving their automobiles (Fowkes, 1995). Those who are taking advantage of the discount are perhaps people who would not have traveled at all under other circumstances.

Such a model demonstrates the limited thinking of UMTs, because it is very one-dimensional. Obviously, transit agencies have a major problem if, upon lowering their fares to zero, few will make a modal change back to mass transit. This approach lacks an understanding of the market and what transit customers want. The perfect solution would be if UMTs could find out how they can increase ridership while increasing revenues and decreasing costs. 


\section{IDENTIFYING THE PROBLEM}

The emphasis must be placed back on enterprise-wide planning and not just on the project itself. UMTs must reclaim their roles as owner-managers of effective urban public transportation. Agencies need to compare a long list of transportation alternatives, including rail, bus, and traffic management measures, along with detailed cost-benefit analyses, financial analyses, and analyses on supplementary policies (ECMT, 1994). Transport for London (TfL), for example, the transportation planning agency responsible for all transportation in London (buses, subways, streets, etc.), has consistently demonstrated the benefits of integrated enterprise-wide planning, especially through its congestion charging program. In order to maximize the capacity of inner-London's transportation network, the mayor of London, Ken Livingstone, integrated the congestion charge with public transportation improvements, parking regulations, traffic calming, intelligent transportation systems, and enhanced facilities for walking and cycling. At the federal level in the U.S., these analyses are also being conducted. However, at the local level (county, state) they are not being done.

What contributes to the poor decisions that UMTs make is not always directly the fault of the UMTs. One of the major roadblocks standing in the way of better transportation management is the type of tools that UMTs use to evaluate projects. These processes have flaws that need to be addressed, because they are usually cost-benefit analyses and are skewed toward supporting high-cost projects. Those projects that are lower-cost and less visible, for instance provisions for bicycling and walking, are usually forgotten in the mix of public transportation planning (Kidd, 2003). The most cost-effective ways through which UMTs can improve are not through major investment, but by making significant marginal changes in the entire UMT enterprise. A marginal problem - for instance, the flow of information within a transit organization - does affect the experience of using the system. Transfer policies, fare policies, the cleanliness of the stations, scheduling, safety and the marketing of the service are all interrelated aspects of public transportation to the customer.

Figure 1 characterizes the current situation for most UMTs. Government, and to some extent the transit customer, provide input to UMTs. In turn, UMTs do their best to try and improve by producing such services as new "rolling stock" (buses, trains, etc.), new technologies (e.g., automated ticketing), and to some extent system expansion (serving new communities, better schedules, etc). The problem is that such changes come at a large cost with small improvements and inconsistent results.

Figure 1

Model Representing Current Management Practices of a Typical UMT

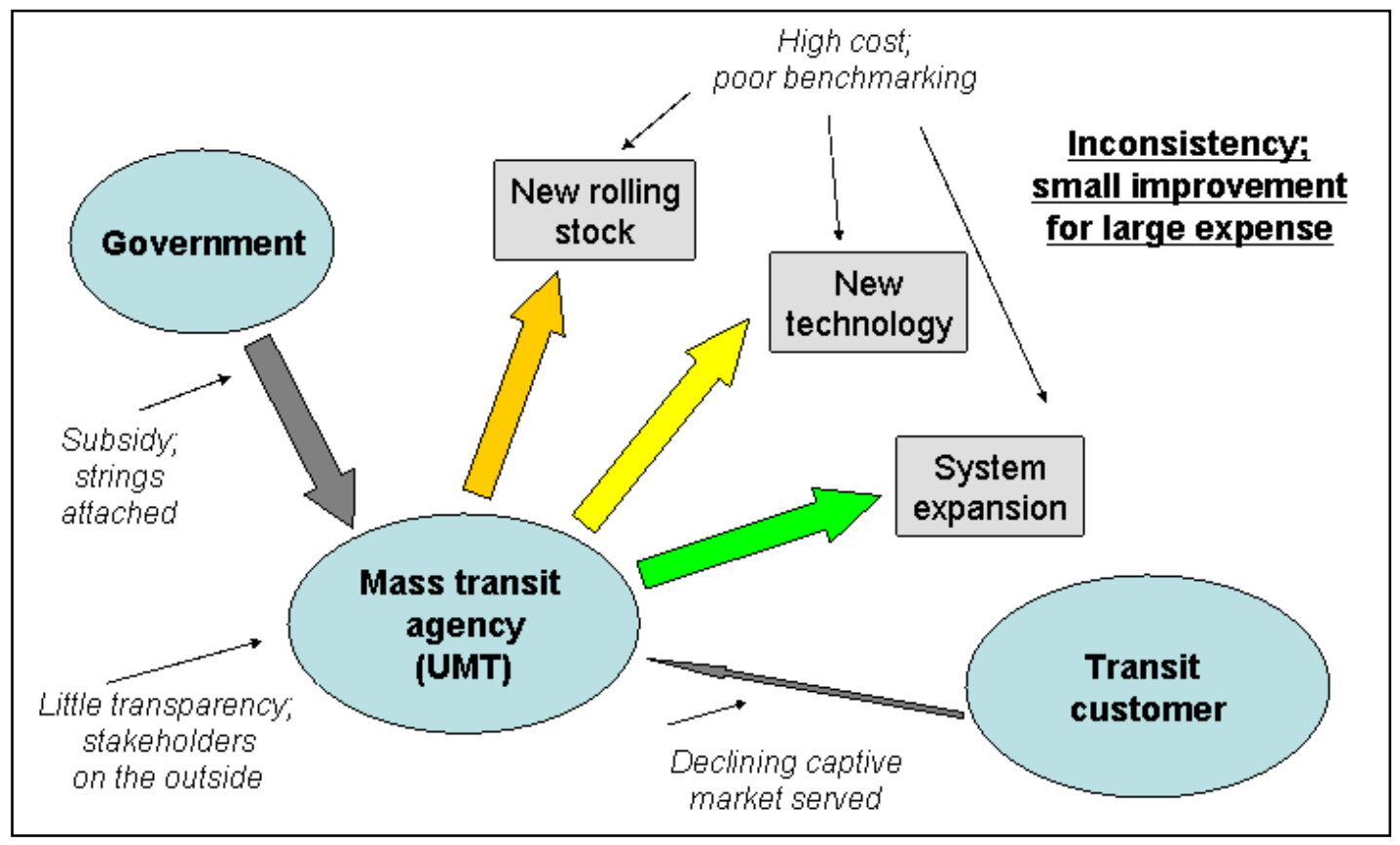




\section{SOLUTION: A LEAN ENTERPRISE ARCHITECTURE APPROACH}

For a successful transformation, Urban Mass Transit agencies require an integrated set of plans, activities, and support documents that execute their enterprise-wide strategic vision, program concepts, acquisition strategy, schedule, communications plan, and implementation strategy. To this end, the authors created the Lean Enterprise Architecture (LEA), which is shown in Figure 2. The LEA [Mathaisel et al 2005] is a structure to organize the activities for the transformation of the entire transit enterprise from a current state to a desired future condition. The LEA uses a phased approach based on the life cycle of the transit system improvements (from cradle to grave) and an enterprise-wide architecture for its transformation. It portrays the flow of phases necessary to initiate, sustain, and continuously refine an enterprise transformation using Lean principles and practices.

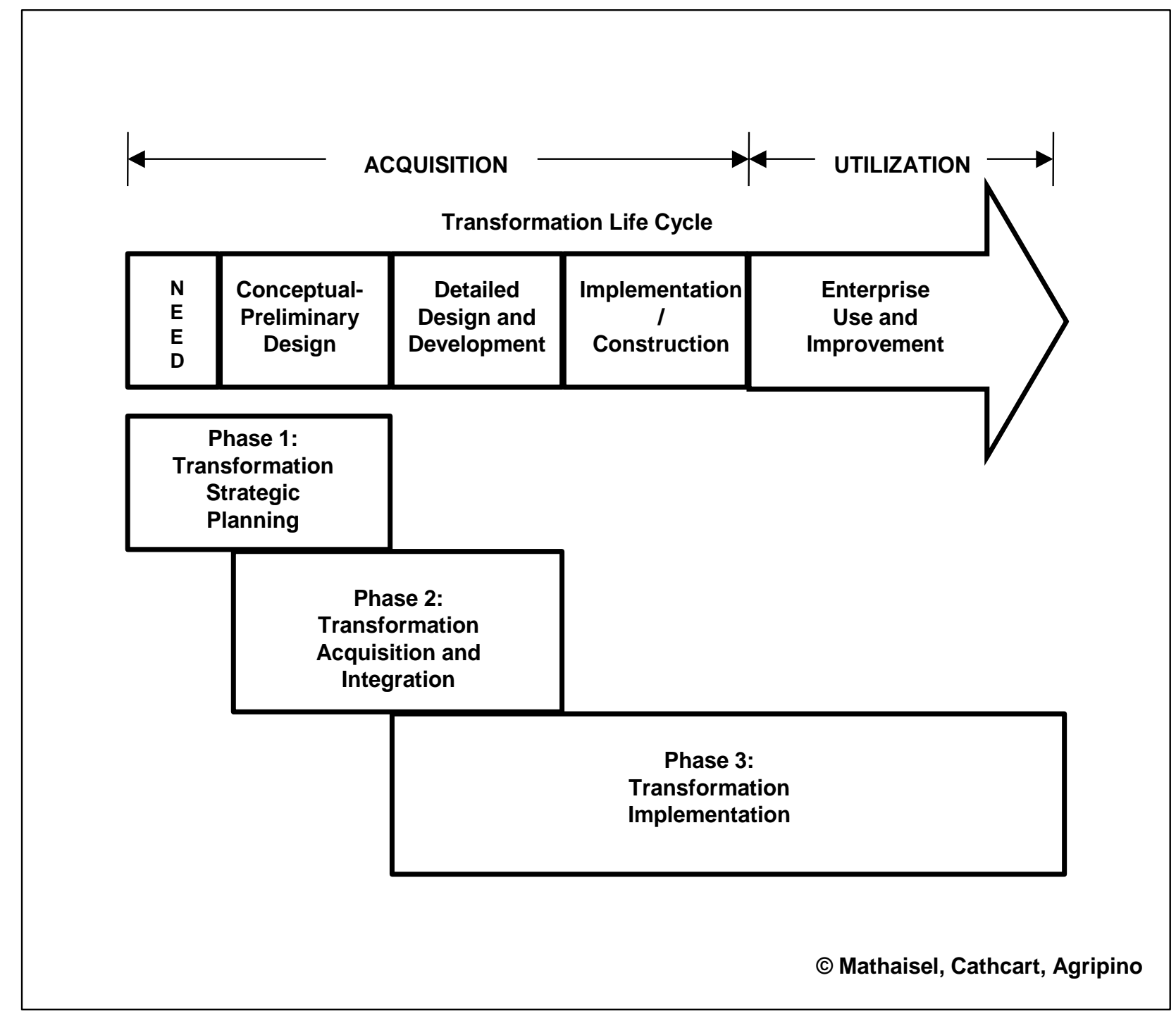

Figure 2

Lean Enterprise Architecture Phases 
The top of the illustration in Figure 2 represents the life cycle of the transformation of the UMT enterprise. The bottom represents the architecture that is used to create the life cycle. The architecture is comprised of three phases (shown at the bottom of the illustration):

1. The first phase is the Transformation Strategic Planning phase, which specifies the actions associated with the decision to adopt the Lean paradigm.

2. The second is the Transformation Acquisition and Integration phase, in which the environment and conditions necessary for a successful change in the enterprise are created.

3. The organization is then prepared for the launch into detailed planning and implementation, which is the third phase, the Transformation Implementation phase, where the transformation of the enterprise is planned, executed, and monitored.

Each phase in this architecture creates the conditions necessary to put into effect the life cycle of the transformation. The description of each component of the life cycle is given in Table 1.

\begin{tabular}{|c|c|}
\hline \multicolumn{2}{|r|}{$\begin{array}{c}\text { Table 1 } \\
\text { Transformation Life Cycle Components } \\
\end{array}$} \\
\hline Component & Description \\
\hline Need & $\begin{array}{l}\text { Wants or Desires for transformation of the enterprise, because of obvious deficiencies } \\
\text { or problems. }\end{array}$ \\
\hline Conceptual and Detailed Design & $\begin{array}{l}\text { Market analysis, feasibility study, requirements analysis, enterprise system design and } \\
\text { development, simulation, engineering prototyping, benchmarking, acquisition plans, } \\
\text { trade-off analysis, and specifications development. }\end{array}$ \\
\hline Implementation / Construction & $\begin{array}{l}\text { Modify, procure, integrate, install, test, train, and implement the transformation of } \\
\text { facilities, production systems, business systems, and policies. }\end{array}$ \\
\hline Enterprise Use and Improvement & $\begin{array}{l}\text { Operational use of the transformation, and continued review for improvement or } \\
\text { modification. }\end{array}$ \\
\hline
\end{tabular}

Since the five principles of Lean Thinking (Womack, 1996) are important ingredients to the architecture, links can be drawn between the components of the framework and the existing Lean tools and techniques. These relationships are identified and further described in Table 2. 


\begin{tabular}{|c|c|c|}
\hline \multicolumn{3}{|c|}{$\begin{array}{c}\text { Table 2 } \\
\text { Relationship between the LEA and the Five Principles of Lean Thinking }\end{array}$} \\
\hline Component & $\begin{array}{l}\text { Relationship to the Five } \\
\text { Principles of Lean } \\
\text { Thinking }\end{array}$ & Discussion \\
\hline Need & (1) Value & $\begin{array}{l}\text { Every enterprise needs to understand what value the customer places upon } \\
\text { their products and services. The Need for the transformation is to } \\
\text { eliminate waste and cost from the business process so that the } \\
\text { transformation can be achieved at great value to the enterprise and its } \\
\text { customers. Value is achieved through the use of the quality tools and } \\
\text { continuous process improvement techniques espoused by Shewart (1989) } \\
\text { (the Plan, Do, Study, Act cycle), Demming (1986) (Total Quality } \\
\text { Management), Harry and Schroeder (2000) (Six Sigma), and many others. }\end{array}$ \\
\hline $\begin{array}{l}\text { Conceptual and } \\
\text { Detailed Design }\end{array}$ & $\begin{array}{l}\text { (2) The Value Stream } \\
\text { and (3) Flow }\end{array}$ & $\begin{array}{l}\text { The value stream is the flow of a product's life cycle from the origin of } \\
\text { the raw materials used to make the product through to the customer's use } \\
\text { and ultimate disposal of the product. In the Conceptual and Detailed } \\
\text { Design component of transforming the enterprise, it is only through a } \\
\text { study of the value stream and its value-added or waste, using techniques } \\
\text { like Value Stream Mapping (Tapping et al, 2002), can an enterprise truly } \\
\text { understand the manufacturing process and/or service. Lean thinking } \\
\text { advocates supplier and customer partnerships and radical supply chain } \\
\text { management to eliminate waste from the entire value stream. } \\
\text { One very significant key to the elimination of waste is flow. If the value } \\
\text { chain stops moving forward for any reason, waste can occur. The } \\
\text { principle of the transformation design is to create a value-stream where } \\
\text { the product, and its raw materials, components, and sub-assemblies, never } \\
\text { stop in the production process, and where each aspect of production and } \\
\text { delivery is fully synchronized with the other elements. Carefully designed } \\
\text { flow across the entire value chain will tend to minimize waste and } \\
\text { increase value. }\end{array}$ \\
\hline $\begin{array}{l}\text { Implementation / } \\
\text { Construction }\end{array}$ & (4) Pull & $\begin{array}{l}\text { During implementation, the way to ensure that nothing is made ahead of } \\
\text { time and builds up work-in-process inventory that stops the synchronized } \\
\text { flow is to use a pull approach. A traditional western manufacturer will use } \\
\text { a Materials Requirements Planning (MRP) or Enterprise Resource } \\
\text { Planning (ERP) style of production planning and control, whereby } \\
\text { production is "pushed" through the factory based upon a forecast and a } \\
\text { schedule. A pull approach states: do not make anything until the customer } \\
\text { orders it. To achieve this requires great flexibility and very short clock } \\
\text { speeds (Fine 1998) in the design, production, and delivery of the products } \\
\text { and services. It also requires a mechanism for informing each step in the } \\
\text { value chain what is required of them today, based upon meeting the } \\
\text { customer's needs. }\end{array}$ \\
\hline $\begin{array}{l}\text { Enterprise Use and } \\
\text { Improvement }\end{array}$ & (5) Perfection & $\begin{array}{l}\text { A lean enterprise sets its target for improvement. The idea of Total } \\
\text { Quality Management (Deming, 1986) is to systematically and } \\
\text { continuously remove the root causes of poor quality from the production } \\
\text { processes, so that the plant and its products are moving towards } \\
\text { perfection. This relentless pursuit of perfection is a key component in the } \\
\text { transformation of an organization that is "striving for lean". }\end{array}$ \\
\hline
\end{tabular}

In what follows below, the authors describe the essential steps and documents that accompany each phase of the Lean Enterprise Architecture. These steps and documents are necessary to initiate, sustain, and continuously refine an Urban Mass Transit enterprise transformation that would result in the implementation of Lean principles and practices. 


\section{Phase 1: Transformation Strategic Planning}

Best commercial and government practices demonstrate the benefits of a Strategic Plan (Table 3) which focuses the effort and energy of an organization toward the achievement of common goals, objectives, and performance metrics. Thus, the first step in a transformation acquisition is to develop a Strategic Plan. The success of the organization is highly dependent upon a focused vision set forth in a carefully conceived plan. The strategic plan should encompass the three crucial change elements of the transformation process: infrastructure, Lean operations, and personnel change management. The Strategic Plan is part of Phase 1 of the LEA.

\section{Table 3 \\ The Strategic Plan}

- Motivates and aligns the organization to achieve common goals and objectives

- Aids tactical planning and execution

- Assists in communications and workforce buy-in

- Supports change planning and management

- Supports development of processes and roadmaps

Phase 2: Transformation Acquisition and Integration

Transformation acquisition necessitates the development of a Requirements Package, an Acquisition Plan, an Integration Plan, and a Change Management and Communication Plan. The Requirements Package (Table 4) consists of a Statement of Objectives/Statement of Work (SOO/SOW) for the transformation, its scope and specifications, a Contract Data Requirements List (CDRL) with acceptance criteria, and a delivery schedule. The package includes: a compelling case for change in UMT processes, procedures and facilities; a clear future state objective; meaningful performance metrics; realistic milestones and accountability; and a clear definition of success. The package addresses the need for urgent cultural transformation and identifies the need for IT integration. The package should also include a requirement to demonstrate and defend the expected return on investment of the transformation against established performance metrics.

\section{Table 4 \\ The Requirements Package}

- Performance-based acquisition strategy

- Performance Work Statement that captures the "what's" not the "how's"

- A compelling case for change

- A clear future state objective for an UMT infrastructure and process

- Meaningful metrics to monitor progress and to drive acquisition objectives

- A clearly stated definition of success (exit criteria)

An Acquisition Plan (Table 5) outlines the strategy for managing the acquisition elements of the transformation. Selection of the transformation contractor should include early and continuous industry involvement, emphasis on past performance, performance-based requirements, oral presentations, cost/benefit analysis, and full and open competition and briefings. The plan must also identify the risks associated with the transformation and develop a mitigation strategy to overcome them. 
Table 5

The Acquisition Plan

- Documents the Acquisition Strategy and high level program structure and schedules

- Acquisition Strategy uses an Evolutionary Acquisition Approach that leverages proven commercial best practices

- System Engineering practices and methodologies are used to design, develop, evaluate, test, integrate, and implement transformation activities

An Integration Plan (Table 6) is also part of Phase 2 of the LEA. Integration encompasses an approach to establishing the appropriate lines of communication: vertically, for those stakeholders directly involved in the implementation of the transformation; and horizontally, to consider the impacts of other productivity enhancement initiatives (e.g., information system upgrades, financial/operational changes, technical support). The plan needs to consider how the transformation will affect, and be affected by, other initiatives. It may require a collaborative software tool that will enhance communications, review, decision-making, and actions taken throughout the affected organizations. The commercially proven Integrated Process and Product Development (IPPD) approach is one tool that can help the transformation achieve its goals more efficiently and effectively by focusing on the integration and application of critical activities early on in the acquisition process. Two key pillars of the IPPD are the Integrated Master Plan (IMP) and Integrated Master Schedule (IMS). Together, these management tools provide the integrated plan of events and activities, the schedule in which these will occur, and the resources that will be used to execute them.

\section{Table 6}

\section{The Integration Plan}

- Establish appropriate lines of communication

- Consider how the transformation will affect, and be affected by, other initiatives

- May require a collaborative software tool to enhance communications

- Use the Integrated Process and Product Development (IPPD) approach

- Develop an Integrated Master Plan (IMP) and Schedule (IMS)

Phase 2 also requires a Change Management Plan (Table 7). The heart of change management is communication. However, communication is effective only when it is focused in the context of an overall change management plan. Therefore, the scope should extend across all areas of change management, including strategy, training, and supporting management systems. A successful UMT transformation depends, in large part, upon how effectively management communicates with those affected by the transformation. This communication must address, at a minimum, what's happening, why it's happening, and how it's happening. More importantly, each individual and organization affected by the transformation must understand how the transformation impacts him or her. There should be, at a minimum, three interrelated communications plans. These plans will be intra-agency, inter-agency, and extra-agency in scope. The intra-agency communication plan should keep all personnel levels at the UMT informed about the transformation status and initiatives. The inter-agency communication plan should keep other government organizations informed about transformation status and initiatives. The extra-agency communication plan should promote and inform the public. Included in a change management/communications plan would be the development and maintenance of a website to include briefings, presentations, contact lists, milestones, mission statement, organizational goals, streaming video shows, collaborative tools, and other public communication tools. 


\section{Table 7}

The Change Management and Communications Plan

- Establish The Motivation For Change And A Sense Of Urgency

- Build A Guiding Coalition

- Develop A Vision And Strategy For Change

- Communicate The Vision

- Empower Broad-Based Action

- Generate Short-Term Wins

- Sustain The Momentum: Consolidate Gains And Produce More Change

- Anchor New Approaches in the Culture

\section{Phase 3: Transformation Implementation}

Transformation implementation is built on a strong centralized vision, continuous improvement, and progress measurement. Successful implementation also requires leadership, innovation, and organization. That basic leadership and organizational framework occurs when the necessary personnel are educated about program management, best commercial Lean practices, financial management, acquisition, source/vendor selection, administrative/office support, and other functions that are deemed necessary to help integrate Government and general contractor personnel efforts. Thus, a good implementation plan (Table 8) is one of: monitoring schedules, performance metrics, and engineering changes; managing risks, costs, and vendor selection; prioritizing payback initiatives and resources; and fostering a sense of urgency in task completion.

\section{Table 8}

\section{The Transformation Implementation Plan}

- Monitor schedules and performance

- Manage risk

- Source selection planning

- Prioritize (and obtain funding for) the highest payback initiatives (measure and ensure ROI)

- Provide program/budget guidance and defend resources

- Implement and monitor the difficult task of embedding cultural change within the UMT.

- Foster a sense of urgency for task completion coupled with a commitment of time and resources and establish metrics that drive the proper behavior

\section{THE RESULT}

The LEA steps and documents are necessary to initiate, sustain, and continuously refine an UMT enterprise transformation that would result in the implementation of Lean principles and practices. According to the LEA approach to transformation, vertical and horizontal integration across the entire enterprise is the key to the whole process. Most public transit agencies neither recognize this principle nor have been able to put it into practice to make a truly integrated, consistent, and smooth operating service.

The LEA Architecture uses a multiphase Lean approach structured on the transformation life cycle and is developed from an enterprise perspective, paying particular attention to strategic issues, internal and external relations with all key stakeholders, and structural issues that must be addressed before and during a significant change initiative. Using this approach to reposition transit agencies in the markets in which they operate would imply that the changes are: 1) low-cost; 2) relatively easy to implement (under the agency's control); 3) high-yield; 4) customer-focused; 5) meet the agency's objective; and 6) performance-measurable. 
The LEA approach can be implemented at a low cost and focuses the attention of UMT management away from poor, high-cost investments. Figure 3 shows what happens to the current situation of Figure 1 when LEA is implemented. It becomes a circle of continuous process improvements (Lean thinking) and has consistent quality.

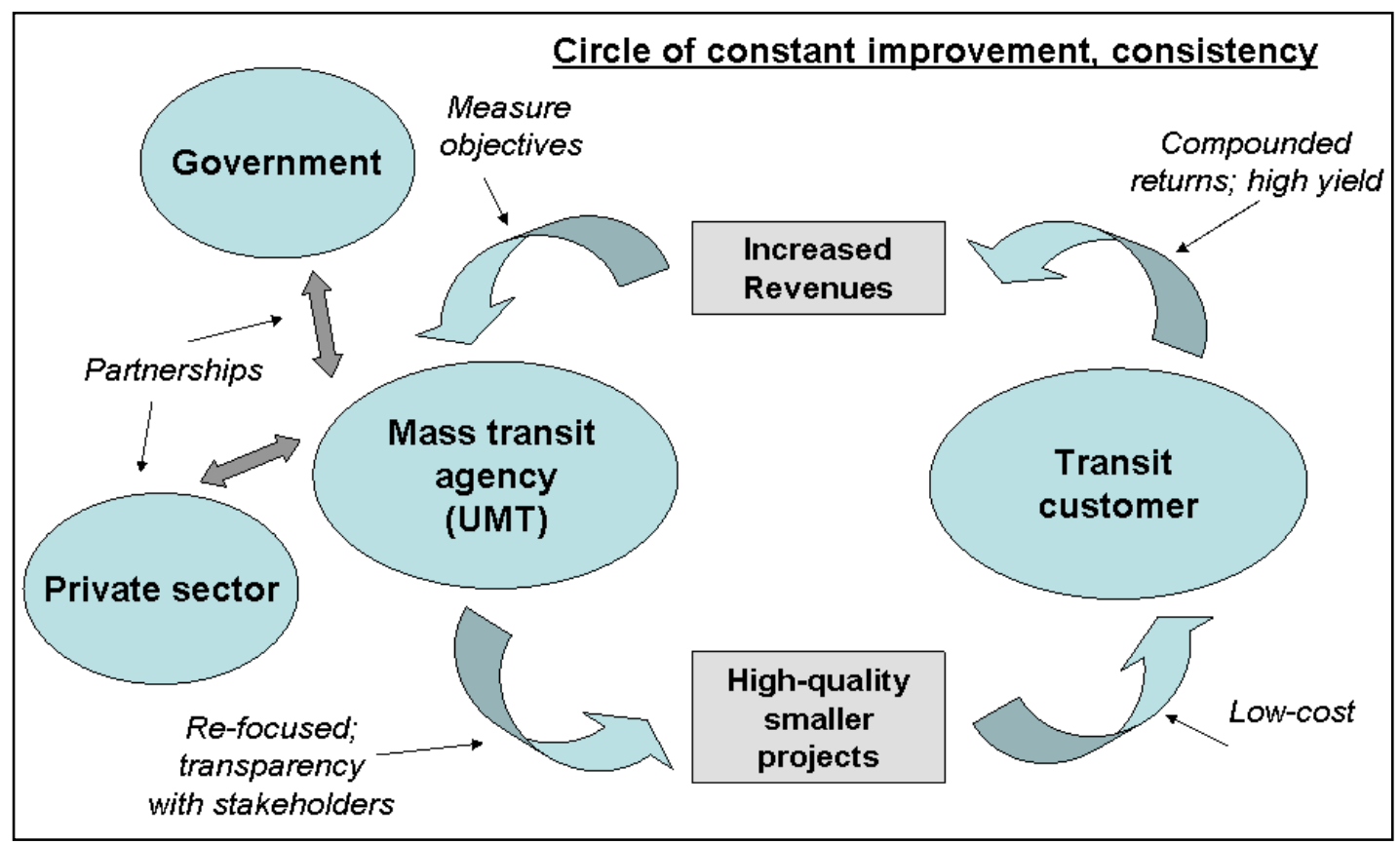

Figure 3

Proposed UMT Customer-Focused Management Transformation Model.

This proposed model accounts for the fact that agencies have limited capital resources, and it represents an environment in which agencies focus on making the most cost-effective improvements to their organizations to position themselves to make larger changes and attract more riders. The belief that radical change is always necessary to "fix" something, like the state of urban mass transit, is not true.

\section{TWO CASE STUDIES}

\section{$\underline{\text { Trent Barton Buses }}$}

An example of a commercial company that decided to revisit the basics along the lines of the LEA approach is Trent Barton Buses, the second-largest bus operator in the region around the cities of Nottingham and Derby, England, running a fleet of 400 buses $^{1}$. Trent Barton is an independent private company, allowing the management to execute what it calls leading-edge marketing. Trent Barton excels in understanding its customers. In fact, the company is so dedicated that one of the exercises it conducts is that it drops its managers in the middle of the city with only $£ 5$ and leaves finding the way back to the office up to them. The knowledge that Trent Barton has gained from carrying out such unorthodox experiments has led it to seek to adopt the business model of a "successful retailer," whose four tenets are: investment, marketing, training, and attention to detail. One of the most visible aspects of the business Trent Barton has dealt with ingeniously is with its vehicle fleet. In its desire to provide a product to its customers that "works," the company decided to make its vehicles as attractive, clean, safe, and accessible as possible (Hopwood, 2003). Its fleet of buses is one of the youngest in the U.K.

\footnotetext{
${ }^{1}$ http://www.trentbuses.co.uk
} 
Another part of the "successful retailer" business model Trent Barton has emulated well from traditionally customer-oriented businesses is the way in which the company trains its employees. Its policy is not to hire bus operators first, but to hire "people-persons" first, and then train them to be vehicle operators. Drivers are trained to be "sympathetic yet firm" through a special "Trent Barton University" set up to teach basic skills, customer care, product knowledge, empowerment and decision-making. After graduating from the "University," bus operators are required to attend refresher courses (Hopwood, 2003).

In addition to sending customer service agents to school, one of the tactics Trent Barton employs is to keep the same drivers on the same routes everyday so they are able to get to know customers and can become experts on their particular routes. The goal of the organization is to have customer service agents who, in being knowledgeable and helpful, are working toward raising customers' expectations. Trent Barton also offers an unconditional moneyback guarantee to its customers. Trent Barton's scheduling and operations are all dependent on what the marketing department finds is best for the customer. It "always acts on the results [of its market surveys] even when they diametrically differ from our own beliefs" (Hopwood, 2003).

Another step Trent Barton has taken to increase the recognition of its brand includes attaching local or catchy names to its routes. For example, some of the names of its routes are "Ilkeston Flyer", "Spondon Flyer", "Rainbow 5", or "The Mickleover." These interesting names have historical significance or were designed to make the buses stand out. In some instances, the name of the bus identifies the frequency of the bus service. Few transit agencies take the time to develop such strong brand recognition.

In order to deliver a quality product, Trent Barton cooperates with local governments to ensure that the infrastructure on which its buses run provides a consistent means for efficient travel. Great lengths are taken to form partnerships with local authorities so Trent Barton can have bus lanes and other priority provisions at its disposal. The authors feel that these concepts are examples of enterprise-wide Lean thinking.

\section{Mexico City's Bus Line}

Another great LEA example of an urban bus line, whose intended result is fast, orderly public transportation, fewer traffic jams and lower emissions, is Mexico City's Insurgentes bus line (Malkin, 2005). It has been in the planning stages for three years and is based on a model developed in Curitiba, Brazil in the 1970's. In this model buses are separated from the other traffic and travel more quickly. This lures commuters from their cars and takes the old smaller buses off the streets, which reduces congestion and allows for better traffic flow. The Mexico City system consists of 80 double-length buses that travel 12 miles each way in dedicated lanes. Special stations are built along the median so customers can step onto the buses from raised platforms and pass fare cards through the turnstiles.

It is estimated by the World Resources Institute's Center for Transport and the Environment that the system costs about $10 \%$ of what a subway would cost (Lean thinking). Many other large cities in the world are considering some versions of this system. Meanwhile, Mexico City's former minibus owners are now part owners and employees of the new system. However, car and taxi drivers do not like the new bus system because the taking away of a lane for the buses slows them down.

\section{CONCLUSION: IMPLEMENTATION OF THE LEA TRANSFORMATION}

Many people around the world still believe public transportation is facing a decline and lack of interest. This statement is a reflection on the limited activity in the market. If urban mass transportation providers could put as much energy and entrepreneurial effort into their product as car manufacturers or airlines, then urban mass transportation would thrive. So, effective communication is critical to the success of a Lean Enterprise Architecture and an UMT agency transformation. For example, recall an incident that occurred in August 2002 aboard an MBTA commuter rail train. As the morning rush-hour train was arriving at a stop on its way to Boston, Massachusetts, a passenger suffered a heart attack. Within one minute, the train crew was notified and a call for help was radioed from the train. The passenger was given CPR by an assistant conductor, but for some reason, the train crew decided 
to make two more scheduled stops before meeting paramedics at the Back Bay station in Boston. The victim received medical attention 17 minutes after he had his heart attack. He died later that morning in the emergency room at Boston Medical Center. The MBTA's general manager admitted that what the train crew did made little sense (Lindsay, 2002). In this case, a giant lack of communication was the problem.

Public agencies, especially those involved in transportation, are heavily criticized for being more reactive than proactive. Communication is a major part of that issue because a transit agency can never care about an issue of which it is unaware. As Gladwell (2000) wrote in The Tipping Point, the environment affects people's behavior. Planning for effective communications is an excellent way of ensuring that people will care and that change will happen.

Urban mass transit agencies need a continuous process improvement strategy (such as that found in the Lean principles) for the entire transit enterprise, which relates to communicating the consistency of their service to their target market. UMTs could not ask for a better time to make a comeback. The governments of developing countries like Mexico and Brazil realize they have problems and are planning for and using more advanced, enterprise-wide, Lean mass transport concepts. The United States, in its Conditions and Performance Report (USDOT, 2003), has stated that it cannot afford to provide for the pace of growth of the automobile. At this time, urban mass transit agencies should take full advantage of these problems by promoting them as opportunities for improvement.

The Lean Enterprise Architecture illustrates key points for implementing the transformation of UMTs. These points are critical to ensuring that continuous process improvement occurs smoothly inside the transit organization and are vital components of the overall architecture. One key point is managing risk. Risk is a necessary part of doing business, and it is essential to the process of innovation. Selling public transit is going to require taking a risk. Little is to be lost, though, and great gains are to be made.

The LEA architecture stresses that providing poor service is more expensive than providing good service. An unresponsive, inefficient organization "increases material costs and decreases the competitiveness of the (agency)" (Mathaisel et al, 2005). Not only is a poorly managed transit agency bad for society, but also a poorly managed agency is bad for itself. From the authors' perspectives, what needs to happen should take place at the highest levels in the organization, and it should happen throughout the entire transit enterprise. Since most UMTs operate as highly bureaucratic top-down organizations, an approach that focuses on strategic issues, internal and external relations with all major stakeholders, and structural issues is the most positive, realistic, and forwardthinking approach that agencies can take. If these issues are addressed, agencies will be able to increase their passengers, revenues, and support because they would be seen as the least costly and most effective alternatives in the urban mass transportation market.

\section{REFERENCES}

1. Deming, W.E., 1986. Out of the crisis: quality, productivity and competitive position, Cambridge University Press: Cambridge.

2. ECMT European Conference of Ministers of Transport, 1994. Light Rail Transit Systems. Paris.

3. Fowkes, A.S., 1995. An investigation into the effects of various transport policies on the levels of motorised traffic in Great Britain in 2006. Working Paper 446, Institute for Transport Studies, University of Leeds, Leeds, England.

4. Gladwell, M., 2000. The Tipping Point: How Little Things Can Make a Big Difference, Little Brown, Boston.

5. Harry, Mikel, and Richard Schroeder, 2000. Six sigma: the breakthrough management strategy revolutionizing the world's top corporations, Double Day Division of Random House, Inc., New York.

6. Hopwood, M., 2003. Trent Barton Buses, Institute for Transport Studies, University of Leeds, Feb.

7. Humphrys, J., 2000. Interview with Steve Norris, On the Record, BBC One, Feb.

8. Jowit, J., 2003. How to think people out of their vehicle, Financial Times Online, LexisNexis ${ }^{\mathrm{TM}}$ Academic, Jan. 
9. $\quad$ Kidd, S., 2003. Appraising short-cuts, dissertation, University of Leeds.

10. Lindsay, J., 2002. Man dies after being forced to wait for help as MBTA train made stops, Boston Globe, July 31.

11. Mackie, P., Preston J., 1998.Twenty-one sources of error and bias in transport project appraisal, Transport Policy 5(1).

12. Malkin, E., 2005. Rumblings at a bus stop: the revolution is running late, New York Times International, July 15, A 4 .

13. Mathaisel, D., Cathcart, T., Agripino, M. 2005. Sustaining the military enterprise: architecture for a lean transformation, Defense Procurement Analysis.

14. Robertson, T., 1967. The process of innovation and the diffusion of innovation, Journal of Marketing, 31, 14-19.

15. Shewhart, Walter,1989. Statistical method from the viewpoint of quality control, Dover Publications.

16. Shoup, D., Brown, J., Hess, D. 2003.Unlimited bus access: an evaluation of the UCLA bruinGO Program and its lessons for California. California Policy Options, 63-88.

17. Tapping, Don, Shuker, Tom, Luyster, 2002. Value stream management, Productivity Press, New York.

18. U.S. Dept. of Transportation, 2002. Status of the nation's highways, bridges, and transit:_conditions and performance, Report to Congress, Washington: GPO, Dec. 27.

19. Womack, J. P., and Jones, D. T., 1996. Lean thinking: banish waste and create wealth in your corporation, Simon and Schuster, New York, NY. 
NOTES 